Bull. Mater. Sci., Vol. 21, No. 1, February 1998, pp. 77-80. (C) Printed in India.

\title{
Preparation of superconducting-grade copper from commercial grade copper salt
}

\author{
P PRAMANIK*, A K ADAK and A PATHAK \\ Department of Chemistry, Indian Institute of Technology, Kharagpur 721302 , India
}

MS received 31 May 1997; revised 28 October 1997

\begin{abstract}
Fine samples with nominal composition of $\mathrm{Bi}_{1.6} \mathrm{~Pb}_{0.4} \mathrm{Sr}_{2} \mathrm{Ca}_{2} \mathrm{Cu}_{3} \mathrm{O}_{x}$ have been produced by solid state method using various purity grades of starting copper oxide powder. Studies on $T_{\mathrm{c}}$ and high- $T_{\mathrm{c}}$ volume fraction measurements of these samples revealed that the samples produced using CuO powders obtained in laboratory after double purification of the commercially available copper salts have higher $T_{\mathrm{c}}(104.46 \mathrm{~K})$ and increased percentage of high $T_{c}$ volume fraction $(58 \%)$ compared to even the samples prepared from Aldrich grade (99.99\%) CuO. A simple and cost-effective chemical route for the purification of $\mathrm{CuO}$ from commercially available copper salts has been outlined.
\end{abstract}

Keywords. Superconductor; high purity copper; chemical purification.

\section{Introduction}

Ever since the discovery of superconductivity in perovskite ceramics (Bednorz and Muller 1986) and later extension of this discovery (Wu et al 1987), there have been large-scale research efforts in this direction the world over. The voluminous research publications in this field stand testimony to the global urge to understand and realize the potentials of these ceramic superconductors. Huge chunks of research funds worldwide are continuously being directed towards the large-scale production of ceramic superconductors having high critical current density $\left(J_{\mathrm{c}}\right)$ and transition temperature $\left(T_{\mathrm{c}}\right)$ into the superconducting phase.

Research into the basic chemistry of these materials are continuing as improvements on the superconducting properties are being sought for. However, some generalizations can now be made for these materials owing to the consistent replication of findings. One such generalized finding is that in all copper oxide based ceramics, the pairing of carriers in the $\mathrm{Cu}-\mathrm{O}_{2}$ planes are responsible for their high $\left(T_{\mathrm{c}}\right)$ superconductivity (Tarascon et al 1987). Thus any substitution on the copper site of these materials, which alters the electronic structures of the $\mathrm{Cu}-\mathrm{O}_{2}$ plane, would tend to strongly depress their $\left(T_{\mathrm{c}}\right)$ (the transition temperature into the superconducting phase or the zero resistance temperature) and the volume fraction of the high $\left(T_{\mathrm{c}}\right)$ superconducting phase (Jones et al 1989). Therefore, impurities, particularly the transition metals $(3 d)$, which have the requisite valencies and ionic radii would tend to replace copper in the $\mathrm{Cu}-\mathrm{O}_{2}$ planes and detriment the superconducting

*Corresponding author properties (Ginsberg 1989; Maeda et al 1990). As a consequence, the purities of the starting materials, particularly the copper salts, used in the preparation of these ceramic superconductors, is expected to play a major role in obtaining a high $T_{\mathrm{c}}$ phase-pure product.

In this paper, we deal with the $\mathrm{Bi}_{1.6} \mathrm{~Pb}_{0.4} \mathrm{Sr}_{2} \mathrm{Ca}_{2} \mathrm{Cu}_{3} \mathrm{O}_{x}$ ceramic superconductor system which is constituted of (2223) phase with $T_{c}$ at $110 \mathrm{~K}$, the (2212) phase with $T_{\mathrm{c}}$ at $80 \mathrm{~K}$, and the (2201) phase with $T_{\mathrm{c}}$ at $20 \mathrm{~K}$. To increase the critical current density $\left(J_{\mathrm{c}}\right)$ above liquid nitrogen temperature, it is important to increase the volume fraction of the high $T_{c}$ phase (i.e. the (2223) phase with $T_{c}$ at $110 \mathrm{~K}$ ) and decrease that of the other phases. Here, we report results of the investigations on the effects of purity of the starting copper oxide on $T_{c}$ and the volume fraction of the high $T_{\mathrm{c}}$ superconducting phase. We also report a cost-effective chemical route for the preparation of high purity grade ( $\geq 99.99 \%)$ copper oxide from commercially available copper salts.

\section{Experimental}

Five different grades of copper oxide powders were used for the preparation of $\mathrm{Bi}_{1 \cdot 6} \mathrm{~Pb}_{0.4} \mathrm{Sr}_{2} \mathrm{Ca}_{2} \mathrm{Cu}_{3} \mathrm{O}_{x}$ samples. The copper oxide powders used were: (i) Copper oxide (98\%) supplied by LOBA Chemie, India, (ii) Copper oxide (98\%) supplied by S.D. Fine Chemicals, India, (iii) Laboratory (single) purified copper oxide from commercially available copper chlorides/sulphates, (iv) Laboratory (double) purified copper oxide from single purified copper and (v) Aldrich grade (99.99\%) copper oxide.

The $\mathrm{Bi}_{1.6} \mathrm{~Pb}_{0.4} \mathrm{Sr}_{2} \mathrm{Ca}_{2} \mathrm{Cu}_{3} \mathrm{O}_{x}$ samples prepared using each of the five mentioned grades of copper oxide powders 


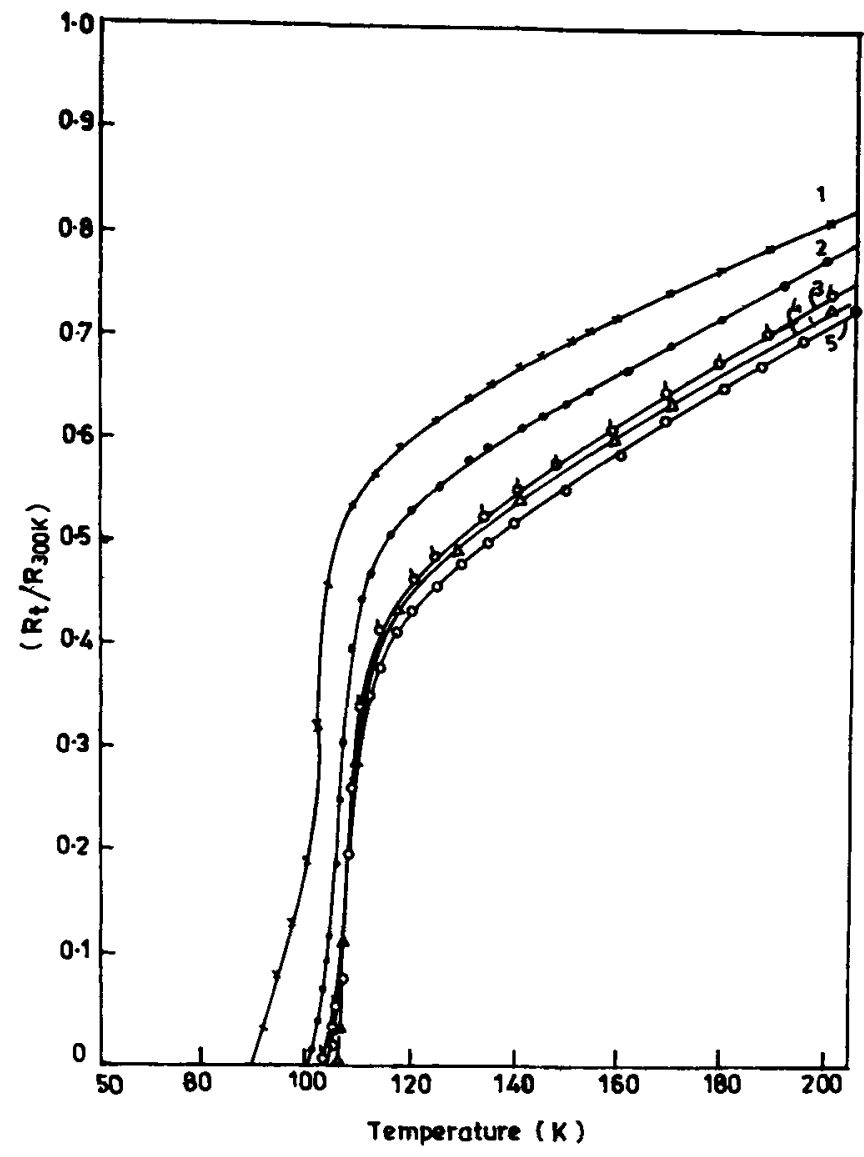

Figure 1. Resistance $\left(R t / R_{300}\right)$ vs temperature $(\mathrm{K})$ plots for $\mathrm{Bi}_{1.6} \mathrm{~Pb}_{0.4} \mathrm{Sr}_{2} \mathrm{Ca}_{2} \mathrm{Cu}_{3} \mathrm{O}_{x}$ samples prepared from $\mathrm{CuO}$ : (1) LOBA Chemie, (2) S.D. Fine Chemicals, (3) Laboratory single purification, (4) Laboratory double purificition and (5) Aldrich. are referred to in the text as samples $1,2,3,4$ and 5 , respectively.

\subsection{Sample preparation}

Stoichiometric amounts of each of these copper oxides were separately taken and mixed with the required amounts of $\mathrm{Bi}_{2} \mathrm{O}_{3}, \mathrm{PbO}, \mathrm{SrCO}_{3}$ and $\mathrm{CaCO}_{3}$. The mixed compositions were then calcined in air at $820^{\circ} \mathrm{C}$ for 24 $\mathrm{h}$. On cooling, the powders were intimately mixed and again calcined in air at $820^{\circ} \mathrm{C}$ for $24 \mathrm{~h}$. On cooling each of the powder compositions were pulverized and pressed into pellets. The pellets were finally sintered at $840^{\circ} \mathrm{C}$ for $100 \mathrm{~h}$ in an atmosphere of $\mathrm{O}_{2}: \mathrm{N}_{2}=1: 10$.

The resistance for each of the pellets were measured by a.c. method using a lock-in-amplifier by the standard four-probe contact method. The temperatures were recorded using a $\mathrm{Cu}$-const thermocouple. The measurement of the (2223) phase volume fraction for each of the pellets were also carried out using a lock-in-amplifier.

\subsection{Purification of copper oxide powders}

To get single purified $\mathrm{CuO}$, the commercially available copper sulphates (or, chlorides), with purity $<98 \%$, was dissolved in distilled water and complexed with sodiumpotassium tartrate (Rochelle salt) in presence of optimum amounts of sodium hydroxide and sodium carbonate. The solution was filtered (to get rid of any turbidity or, suspended impurities) so as to get a clear blue coloured filtrate. The filtered solution then refluxed with $40 \%$

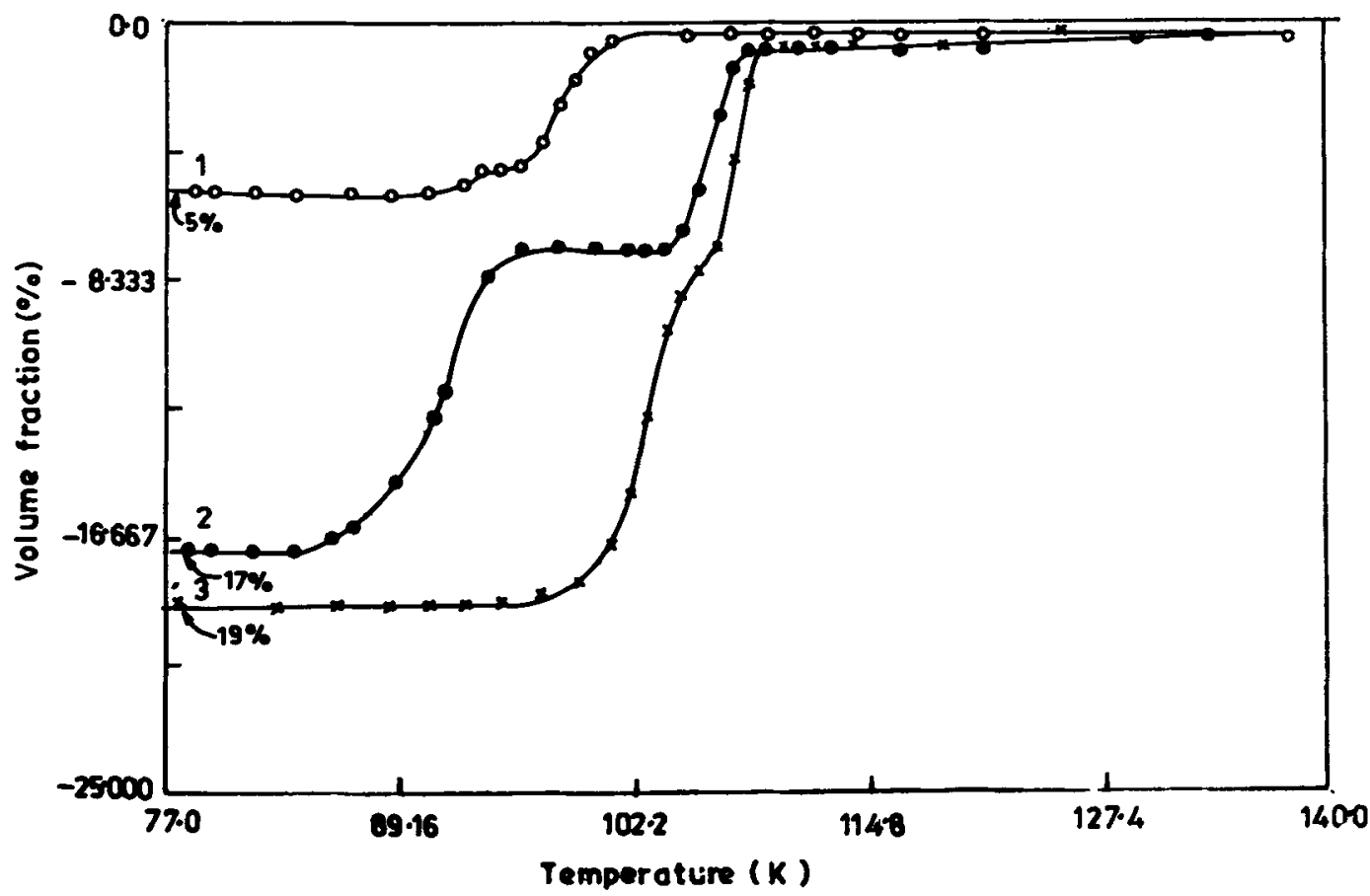

Figure 2. High $T_{c}$ volume fraction (percentage) vs temperature (K) plots for $\mathrm{Bi}_{16} \mathrm{~Pb}_{0.4} \mathrm{Sr}_{2} \mathrm{Ca}_{2} \mathrm{Cu}_{3} \mathrm{O}_{x}$ samples prepared from CuO: (1) LOBA Chemie, (2) S.D. Fine Chemicals and (3) Laboratory single purification. 


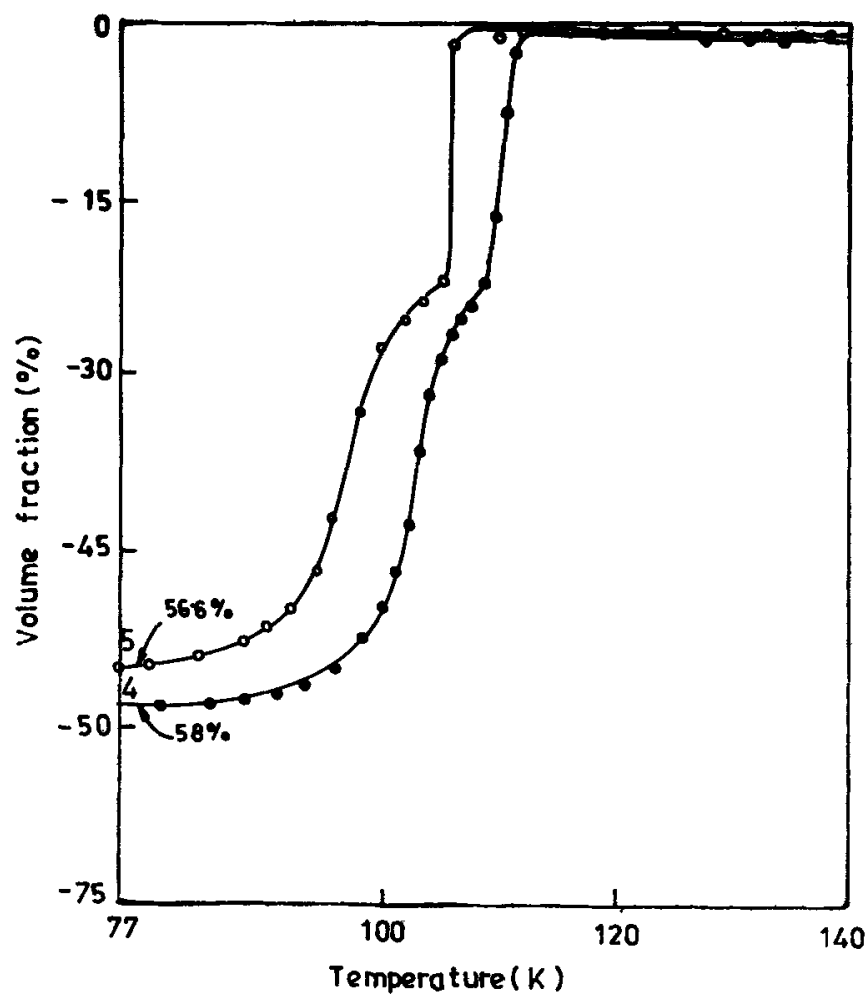

Figure 3. High $T_{c}$ volume fraction (percentage) versus temperature (K) plots for $\mathrm{Bi}_{1.6} \mathrm{~Pb}_{0.4} \mathrm{Sr}_{2} \mathrm{Ca}_{2} \mathrm{Cu}_{3} \mathrm{O}_{x}$ samples prepared from $\mathrm{CuO}$ : (4) Laboratory double purification and (5) Aldrich. formaldehyde (with ratio $5: 1$ ) over a water bath. Reddish metallic copper precipitated within $10-15 \mathrm{~min}$ of refluxing. The metallic copper was then separated and dried with acetone. Calcination (in air) at $400^{\circ} \mathrm{C}$ for $3 \mathrm{~h}$, of the metallic copper gave the single purified $\mathrm{CuO}$ powder.

To obtain double purified $\mathrm{CuO}$, the precipitated copper mentioned above was dissolved in chlorine water and the entire process from separation of copper from the solution to calcination in air was repeated.

\section{Results and discussion}

The fall of resistance with temperature were recorded for each of the $\mathrm{Bi}_{1 \cdot 6} \mathrm{~Pb}_{0.4} \mathrm{Sr}_{2} \mathrm{Ca}_{2} \mathrm{Cu}_{3} \mathrm{O}_{x}$ compositions prepared from varied purity of $\mathrm{CuO}$ and are depicted in figure 1 . From the measurements, it was observed that the sample prepared from LOBA Chemie grade $\mathrm{CuO}$ (i.e. sample 1) had the lowest $T_{\mathrm{c}}(R=0)$ while the sample from double purified $\mathrm{CuO}$ (i.e. sample 4) and Aldrich $\mathrm{CuO}$ (i.e. sample 5) had higher and comparable $T_{\mathrm{c}}$ values. The fall in resistance with temperature (figure 1) in the case of samples 1 and 2 were not very sharp, reflecting the presence of phases other than the (2223) as the major phase. On the other hand, relatively sharper fall in resistance in samples 3,4 and 5 were indicative of the realization of the (2223) as the major phase.

The details of the volume fraction of the (2223) phase for the various $\mathrm{Bi}_{1.6} \mathrm{~Pb}_{0.4} \mathrm{Sr}_{2} \mathrm{Ca}_{2} \mathrm{Cu}_{3} \mathrm{O}_{x}$ samples are

Table 1. $T_{\mathrm{c}}(R=0)$ and percentage volume-fraction of the (2223) phase for various samples of $\mathrm{Bi}_{1 \cdot 6} \mathrm{~Pb}_{0.4} \mathrm{Sr}_{2} \mathrm{Ca}_{2} \mathrm{Cu}_{3} \mathrm{O}_{x}$.

\begin{tabular}{|c|c|c|c|}
\hline Sample & Source of $\mathrm{CuO}$ & $T_{\mathrm{c}}$ & $\begin{array}{l}\text { Percentage volume } \\
\text { fraction }\end{array}$ \\
\hline 1 & LOBA Chemie, India $(98 \%)$ & $89 \cdot 30 \mathrm{~K}$ & $5.0 \%$ \\
\hline 2 & S.D. Fine Chemicals $(98 \%)$ & $99.20 \mathrm{~K}$ & $17.0 \%$ \\
\hline 3 & Single purified & $102.98 \mathrm{~K}$ & $19.0 \%$ \\
\hline 4 & Double purified & $104.46 \mathrm{~K}$ & $58.0 \%$ \\
\hline 5 & Aldrich Grade $(99.99 \%)$ & $104.44 \mathrm{~K}$ & $56 \cdot 6 \%$ \\
\hline
\end{tabular}

Table 2. Analysis of the impurities present in the various grades of $\mathrm{CuO}$ powder.

\begin{tabular}{|c|c|c|c|c|c|}
\hline \multirow[b]{2}{*}{ Impurity } & \multicolumn{5}{|c|}{ Percentage present } \\
\hline & $\begin{array}{l}\text { LOBA } \\
\text { Chemie }\end{array}$ & $\begin{array}{l}\text { S.D. Fine } \\
\text { Chemicals }\end{array}$ & $\begin{array}{c}\text { Single } \\
\text { purified }\end{array}$ & $\begin{array}{l}\text { Double } \\
\text { purified }\end{array}$ & Aldrich \\
\hline $\mathrm{Fe}$ & $0 \cdot 1321$ & 0.0580 & 0.0120 & 0.0020 & 0.0030 \\
\hline $\mathrm{Zn}$ & $1 \cdot 4250$ & 0.0355 & 0.0246 & 0.0052 & 0.0040 \\
\hline $\mathrm{Ni}$ & 0.0525 & 0.0135 & 0.0221 & 0.0060 & 0.0060 \\
\hline $\mathrm{Co}$ & 0.0932 & 0.0162 & 0.0047 & 0.0032 & 0.0030 \\
\hline Mn & 0.0324 & 0.0021 & 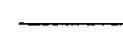 & Not detectable & \\
\hline $\mathrm{Cr}$ & 0.0201 & 0.0020 & & Not detectable & ـــــ \\
\hline $\mathrm{Se}$ & 0.0943 & 0.0240 & & $<0.001$ & - \\
\hline $\mathrm{Te}$ & 0.0762 & & & $<0.001$ & 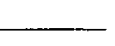 \\
\hline
\end{tabular}


represented in figures 2 and 3 . The formation of steps in the volume fraction versus temperature curves are manifestations of the presence of (2212) phase along with (2223) phase. From figure 2 , it is conclusive that in sample 1 very little of the (2223) phase exists in the sample. The striking feature of figure 3 reveals that the sample 4 , prepared from double purified $\mathrm{CuO}$, has a higher percentage volume-fraction of the (2223) phase compared to that of sample 5, which was prepared from Aldrich-grade $(99.99 \%)$ CuO.

The $T_{\mathrm{c}}(R=0)$ values and their respective percentage volume-fraction of the (2223) phase for the various samples of $\mathrm{Bi}_{1.6} \mathrm{~Pb}_{0.4} \mathrm{Sr}_{2} \mathrm{Ca}_{2} \mathrm{Cu}_{3} \mathrm{O}_{x}$, prepared from various grades of $\mathrm{CuO}$ are summarized in table 1 .

The atomic absorption data for the various grades of $\mathrm{CuO}$ powders revealed the presence of $\mathrm{Zn}, \mathrm{Ni}, \mathrm{Fe}$ and trace amounts of $\mathrm{Co}, \mathrm{Se}$ and $\mathrm{Te}$ as trace impurities. The impurities present were the maximum for the $\mathrm{CuO}$ powders supplied from the LOBA Chemie, India while it was the minimum for the double purified $\mathrm{CuO}$. The analysis of impurities present in double purified $\mathrm{CuO}$ determined by automic absorption spectroscopy (AAS) is given in table 2. The order of increase of purity in $\mathrm{CuO}$ powders were as follows:

LOBA Chemie < S.D. Fine Chemicals < Single purified $\ll$ Aldrich-Grade $\leq$ Double purified.

Presence of impurities, such as $\mathrm{Zn}, \mathrm{Ni}$ and $\mathrm{Fe}$, in the starting $\mathrm{CuO}$ powders provided scope for their substitution for the $\mathrm{Cu}$ sites. With increased levels of impurities their chances of replacing $\mathrm{Cu}$ in the $\mathrm{Cu}$ sites were increased and the electronic structure of the $\mathrm{Cu}-\mathrm{O}_{2}$ plane was expected to get altered. Consequently, the $T_{\mathrm{c}}$ values and the percentage volume fraction of the (2223) phase got depressed.

Supplementing with the atomic absorption data, it can be concluded that higher purity of the starting $\mathrm{CuO}$ leads to higher values of $T_{\mathrm{c}}$ and increased volume fractions of high $T_{c}$ phase. It can also be concluded that double purification of copper oxide by simple chemical route indeed leads to a better superconducting final material. The chemical route used for single and double purification requires commonly available and less costly chemical reagents such as formaldehyde, sodium-potassium tartrate, $\mathrm{NaOH}$ and $\mathrm{Na}_{2} \mathrm{CO}_{3}$ thus making the route costeffective for large scale production of high-purity copper oxide.

\section{References}

Bednorz J G and Muller K A 1986 Phys. B: Condens. Matter 64189

Ginsberg D M 1989 Physical properties of high temperature superconductors 1 (Singapore: World Scientific)

Jones T E, Thibado P M, McGinnes W C, Boss R D, Schindler J W and Oseroffs S 1989 Physica C162 25

Maeda A, Yabe T, Tukebayashi S, Hase $M$ and Uchinokura $\mathrm{K}$ 1990 Phys. Rev. B41 4112

Tarascon J M et al 1987 Phys. Rev. B36 8393

Wu M K et al 1987 Phys. Rev. Lett. 58908 